\title{
CONSCIENTIZAÇÃO AMBIENTAL NAS EMPRESAS: BENEFÍCIOS POSITIVOS PARA AS ORGANIZAÇÕES E PARA OS TRABALHADORES
}

ENVIRONMENTAL AWARENESS IN THE COMPANIES: POSITIVE BENEFITS FOR THE ORGANIZATIONS AND THE WORKERS

CONCIENTIZACIÓN AMBIENTAL EN LAS EMPRESAS: BENEFICIOS POSITIVOS PARA LAS ORGANIZACIONES Y PARA LOS

TRABAJADORES

Rodrigo Florencio da SILVA

\section{RESUMO}

Este artigo tem o objetivo de mostrar um estudo de caso realizado em diferentes companhias na cidade do México sobre a conscientização ambiental e a função da Educação Ambiental nas empresas. Os benefícios positivos tanto para os estabelecimentos como para os funcionários serão apresentados e se discutirá a importância de ter uma capacitação e formação sobre a identificação dos impactos e problemas ambientais que o mundo enfrenta, como também as possiveis ações de solução para ditas afetações, as mudanças positivas de atitudes que refletirão no meio ambiente e o papel das empresas na redução dos impactos ambientais.

PALAVRAS-CHAVE:

Conscientização Ambiental;

Empresa; Sustentabilidade; Educação Ambiental.

\section{ABSTRACT}

This paper refers to a case study carried out in different companies in Mexico City on environmental awareness in the companies and the role of Environmental Education. The positive benefits for the corporations and the employees will presented and discussed also the importance of training on the identification of environmental impacts and problems facing the world, the possible actions to resolve these impacts, the positive changes in attitudes that will reflect on the environment and the role of companies in reducing environmental impacts.

\section{KEYWORDS:}

Environmental Awareness; Company; Sustainability; Environmental

Education.

\section{RESUMEN}

Este artículo tiene el objetivo de mostrar un caso de estudio realizado en diferentes compañías en la ciudad de México acerca de la concientización ambiental y el rol de la Educación Ambiental en las empresas. Los beneficios positivos tanto para los establecimientos como para los empleados serán presentados y se discutirá la importancia de tener una capacitación y formación sobre la identificación de los impactos y problemas ambientales que el mundo enfrenta, como también las posibles acciones de solución para dichas afectaciones, los cambios positivos de actitudes que reflejarán en el medio ambiente y el papel de las empresas en la reducción de los impactos ambientales.

PALABRAS-LLAVE:

Concientización; Empresa;

Sustentabilidad; Educación Ambiental. 


\section{INTRODUÇÃO}

É importante atualmente que as indústrias, empresas e companhias atuem de forma sustentável, reduzindo o seu impacto ambiental no ambiente. É evidente a preocupação sobre a questão ambiental que o mundo enfrenta e através da Educação Ambiental é possível conscientizar e gerar uma mudança de atitude e comportamento nas pessoas sobre os problemas ambientais que acontecem no nosso planeta hoje.

Mrazek (1996) afirma que a Educação Ambiental é definida como um processo interdisciplinar que tem por finalidade desenvolver cidadãos conscientes e informados sobre o meio ambiente em sua totalidade e em seu aspecto natural e modificado, com capacidade para assumir o compromisso de participar na solução de problemas, tomada de decisões e atuar para garantir a qualidade ambiental.

Dos Santos e Gould (2018) comentam que a Educação Ambiental inclui uma variedade de práticas e objetivos, possibilitando uma interação humana com o resto do planeta de forma mais sustentável.

A Educação Ambiental nas empresas tem um papel fundamental de sensibilização e de motivação porque leva os funcionários a buscar soluções e respostas para a problemática ambiental que o mundo enfrenta.

As indústrias e empresas geram impactos ambientais que requerem ações sustentáveis para solucioná-las. Para Florencio da Silva e Garcia-Serrano (2017), o papel da Educação Ambiental nas empresas e industrias é de gerar benefícios para o local de trabalho e também para o trabalhador já que é possível aplicar esse conhecimento e aprendizagem sobre o cuidado do meio ambiente em casa.

Quando a Educação Ambiental é aplicada dentro da empresa, proporciona inúmeros benefícios para todos os envolvidos em suas atividades. Por isso, todos os trabalhadores devem conhecer quais são os indicadores ambientais da companhia e os riscos de contaminação que podem ser gerados caso a empresa não cumpra com as normas estabelecidas pelos órgãos controladores.
Deste modo, a Educação Ambiental com os trabalhadores de uma empresa possibilita a conscientização sobre a necessidade de ter equipamentos tecnológicos que não contaminem o ambiente, da economia de água e eletricidade, mudanças de atitudes sobre a utilização de insumos e produtos que podem ser substituídos por processos mais eficientes e da separação dos lixos.

É possível mencionar que quando os trabalhadores estão conscientes da necessidade de repensar processos obsoletos em seu local de trabalho como trocar máquinas e equipamentos que contaminam e poluem por novas tecnologias que não causem danos ao meio ambiente, haverá mudanças positivas referentes à parte ambiental no dia a dia da empresa.

Uma das finalidades da Educação Ambiental é informar e sensibilizar às sociedades para que gradualmente seus integrantes desenvolvam uma consciência sobre as causas, consequências e origens dos diferentes problemas ambientais existentes, fazendo com que esse conhecimento adquirido "contribua ao estabelecimento de valores ambientais e também para a melhoria das condições do meio ambiente" (CALIXTO FLORES, 2015, p.12).

Nas companhias e empresas, a Educação Ambiental assume um papel importante de formar e capacitar os trabalhadores para reconhecer os problemas ambientais e de tomar decisões para a soluções dos mesmos.

Uma empresa sustentável é aquela que procura o sucesso em diferentes aspectos, com base no controle da qualidade dos produtos gerados, observando a origem de seus insumos e tendo como meta o bem-estar dos seus funcionários e colaboradores, além de reconhecer o impacto social e econômico de suas atividades. Barba e Solís (2000) definem uma empresa sustentável como a que tem um modelo de trabalho que gera ações de responsabilidade com o meio ambiente e inova em sua produção com produtos que não agridem o meio ambiente.

Esta pesquisa aborda um trabalho realizado em diferentes empresas no México sobre a conscientização ambiental nas empresas e industrias, o papel da educação na formação dos trabalhadores e os benefícios que essas ações trazem para todos os envolvidos.

\section{VISITANDO AS EMPRESAS PARA CONHECER AS AÇÕES SUSTENTÁVEIS}

As companhias amigas do meio ambiente estão conquistando mais espaço no mercado e a confiança dos seus clientes. Com isso, é importante que seus trabalhadores conheçam as ações sustentáveis que realizam as empresas, tenham conhecimento do impacto ambiental e saibam como reduzi-lo.

Para este artigo, foram convidados e entrevistados 70 trabalhadores de diferentes empresas e ramos de atividades, no intuito de compreender o papel da Educação Ambiental dentro das atividades das companhias e o seu benefício para o meio ambiente.

A escolha dos participantes ocorreu a partir de uma lista publicada (tabela 1 a seguir) na revista de circulação no México, Expansión, edição de janeiro de 2019, que trazia as 100 empresas mais sustentáveis do mundo. Foram selecionadas algumas empresas presentes no México e contataram-se algumas delas para que seus trabalhadores participassem deste estudo.

Foram visitadas cinco empresas das áreas de cosmético, serviços, gestão de resíduos, alimentação, embalagem e transporte, que permitiram a realização deste estudo durante quatro meses, totalizando dez encontros de uma hora cada um. O número de sessões foi igual em todas as empresas selecionadas e a finalidade do encontro foi de discutir com os participantes a importância da educação ambiental no trabalho, a conscientização sobre os problemas ambientais e a importância da conservação do meio ambiente, enfatizando os problemas e desafios na questão da mudança climática

Foi explicado aos trabalhadores dessas empresas que as condições de participação nesta pesquisa era ser funcionário da empresa, a permanência durante as visitas e a disposição para participar.

As principais perguntas e temas realizados durante as sessões eram se os trabalhadores reconheciam os problemas e impactos ambientais que afetavam o mundo, a 


\begin{tabular}{|c|c|}
\hline Empresa & Setor \\
\hline CHR Hansen & Biociência \\
\hline Kering & Artículos de luxo \\
\hline Neste & Refinados de petróleo \\
\hline Ørsted & Energia \\
\hline GlaxoSmithKline & Real Estate \\
\hline Prologis & Tecnologia de materiais \\
\hline Umicore & Banco \\
\hline Banco do Brasil & Banco \\
\hline Shinhan Financial Group & Semicondutores \\
\hline Taiwan Semiconductor & Serviços profissionais e educativos \\
\hline Pearson & Tecnologia de manufatura \\
\hline Outotec & Alimentos e bebidas \\
\hline McCormick \& Company & TI \\
\hline Cisco Systems &
\end{tabular}

Tabela 1: Adaptação da lista das empresas mencionadas pela revista Expansión (2019).

região da empresa e a de seu domicilio, questionando se alguma das ações para minimizar esses impactos era realizada pela companhia a qual trabalhavam.

Durante os encontros, utilizaram-se vídeos didáticos, reportagens, atividades lúdicas e leituras para reforçar a discussão e entendimento do tema.

Para o desenvolvimento da pesquisa, foi elaborado um questionário com 40 perguntassobreasatividadesdacompanhia, sobre as ações de sustentabilidade adotadas, o impacto ambiental, soluções dos problemas ambientais, aplicações das ações aprendidas no serviço e em outros locais fora do local de trabalho, além da importância de capacitações para os temas ambientais e de concursos culturais que envolvem os trabalhadores e sua família, no intuito de analisar a importância de se ter a Educação Ambiental como aliada das empresas.

Realizou-se antes da entrega do questionário uma sessão explicativa sobre as perguntas contidas no instrumento de pesquisa e a necessidade de que as respostas fossem de acordo com a experiência vivida na empresa. As opiniões e sugestão de novas práticas também foram solicitadas e os participantes deveriam responder as perguntas dando exemplos e argumentando sobre cada resposta dada.

Foi estipulada uma duração de 2 horas para a resolução do questionário e ao terminar o tempo, o instrumento de pesquisa era recolhido e entregue ao aplicador. As respostas e argumentos dos participantes foram analisadas para serem comentadas a seguir.

\section{A IMPORTÂNCIA DA EDUCAÇÃO AMBIENTAL NAS COMPANHIAS}

Dado que os encontros realizados com os participantes tinham como objetivo favorecer a aproximação e a conscientização do impacto e problemática ambiental com os trabalhadores e reforçar a importância do papel da Educação Ambiental nas empresas, notou-se que os funcionários participantes estavam sensibilizados e preocupados com os problemas ambientais atuais.

Durante a análise das respostas do questionário, identificaram-se as diferentes ações que as empresas realizavam.

Após a aplicação do questionário, foi possível conhecer as preocupações dos participantes sobre o impacto ambiental e as ações realizadas pelas companhias. Notou-se que existia aprendizagem sobre esses temas por meio das capacitações realizadas e que muitos dos trabalhadores aplicavam os conhecimentos aprendidos em suas casas.

Descrevem-se aqui as principais ações relatadas pelos participantes que são consideradas importantes e que trazem benefícios para o meio ambiente:

Os funcionários de uma companhia da área de alimentação relataram de forma positiva um projeto do restaurante que pretendia reutilizar o óleo de fritura e que poderia ser utilizada no transporte, gerando economia de combustível. Foi comentado também que a empresa os capacitou e simulou o dano que provoca se o óleo for derramado diretamente no meio ambiente. Os empregados relataram o conhecimento adquirido através das capacitações e aprenderam sobre outras finalidades que podem ser dadas ao óleo depois de descartado. Foram comentadas diferentes ações sustentáveis e conhecimentos sobre formas de minimizar o impacto ambiental.

De acordo com Guerra et al (2018), a Educação Ambiental promove a consciência e a informação sobre a sustentabilidade, promovendo o pensamento crítico e o comportamento ecológico.

Um outro grupo de trabalhadores da área de alimentos comentou sobre diversas ações para a sustentabilidade. Uma delas é o processo de troca de combustível usado nas caldeiras industriais por óleo vegetal derivado dos resíduos de soja. Os participantes dessa companhia também comentaram através do questionário que a capacitação recebida incluiu temas sobre as energias renováveis e puderam participar e ver a instalação de placas solares. Além disso, puderam acompanhar durante meses os relatórios mensais de economia de energia que a empresa estava obtendo ao utilizar a energia solar. $\mathrm{O}$ mesmo grupo destacou também a economia de água através da reutilização e o tratamento que a empresa realizava antes da sua reutilização. Muitos dos participantes relataram a importância de conhecer as ações sustentáveis e que aprenderam sobre essas práticas porque foram formados e conscientizados sobre o meio ambiente.

Através das respostas e comentários dos funcionários, percebeu-se que ao serem capacitados na empresa sobre as ações 
sustentáveis que a companhia adotava, tornavam-se mais sensíveis e preocupados em relação aos problemas ambientais.

Para Jennings (2009), a educação sobre energia renovável é um campo importante e essa educação energética inclui um estudo da tecnologia, recursos, economia, estrutura e leis.

Uma das ações consideradas importantes pelos trabalhadores de uma empresa de gestão de resíduos foi a capacitação sobre os lixos e a sua manipulação. Os entrevistados da empresa comentaram que aprenderam sobre como classificar cada lixo, o tempo que leva para a degradação e o impacto que pode causar no meio ambiente. Os funcionários desse estabelecimento afirmaram que é muito importante que as companhias gerenciem e aproveitem ao máximo tudo que entra na empresa e que dê um fim sustentável ao lixo. Foi comentado também que eles aplicam esse conhecimento em suas residências e que suas famílias começam a ter novos hábitos sobre o meio ambiente após a iniciativa aprendida no local de trabalho.

Já o grupo de uma companhia de embalagem ressaltou um projeto, considerado por eles muito importante, que é a confecção de bolsas através de plásticos e embalagens jogadas no lixo. Os trabalhadores utilizavam essas bolsas para diferentes atividades, substituindo o consumo de sacolas plásticas em supermercados por bolsas distribuídas pela empresa. Esse grupo de funcionário foi capacitado e passou por um curso de

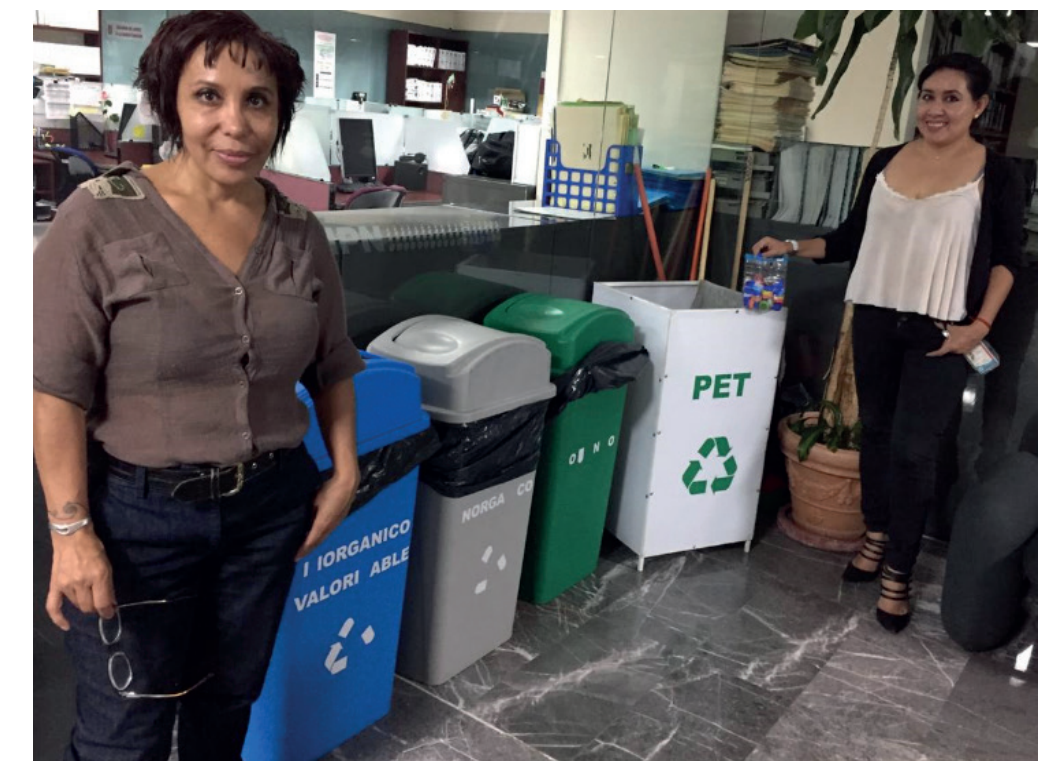

Educação Ambiental, conscientizando-se sobre a problemática do plástico e o tempo de degradação no meio ambiente, além da necessidade de reciclar e de dar um fim

Os colaboradores de uma empresa de transporte descreveram ações relacionadas à troca de lâmpadas tradicionais pelas de LED. Os participantes mencionaram os cursos realizados dentro da empresa e souberam das vantagens em utilizar as lâmpadas de LED. Além da questão da economia, os trabalhadores mencionaram a durabilidade e eficiência de utilizar esse tipo de lâmpada.

Encontrou-se também nas respostas uma empresa de cosmético que monitorava o ciclo de vida das embalagens dos seus produtos. Os funcionários consideravam a ação fundamental, porque além de utilizar papel reciclado, a empresa retirava de circulação os materiais promocionais e as embalagens já utilizados para enviar à reciclagem. Os participantes comentaram diversas ações de sustentabilidade em que a fábrica onde trabalhavam reduzia as emissões provenientes das atividades da empresa. Foi possível notar através das respostas que as capacitações e cursos proporcionados pela empresa deixaram uma marca positiva nesses trabalhadores que se mostraram conscientes sobre ações que reduzem o impacto no meio ambiente.

Os entrevistados da área de serviço relataram que o cuidado com o meio ambiente se aplica diariamente e que receberam formação sobre a importância da água e seu reuso, das energias positivo a esses materiais. renováveis e dos produtos biodegradáveis. Os participantes presenciaram a criação de um prédio que possuía uma cisterna que recolhia água da chuva, captando energia solar e de madeiras colhidas em diferentes demolições. Os funcionários classificavam essas ações da empresa como necessárias e importante devido a transmissão de responsabilidade para todos os colaboradores.

Um ponto em comum em muitas respostas foi que as empresas promoviam a importância da locomoção em bicicletas e as caronas para irem ao trabalho e para casa. Comentaram também que recebiam copos de vidros para beber água, extinguindo os copos de plásticos e de isopor. Foi mencionado em muitas respostas a importância de economizar papel e que antes de imprimir deveriam refletir se realmente era importante a impressão. Comentaram também sobre a prática do envio de e-mails e o reaproveitamento das folhas impressas para novas impressões.

Uma prática comum relatada em muitas respostas foi a troca de equipamentos obsoletos por máquinas novas que reduzem o consumo de energia e não contaminam o meio ambiente. Para os participantes, a adoção de equipamentos com novas tecnologia contribui para a solução dos problemas ambientais e demonstra que a empresa está preocupada com as gerações futuras.

\section{CONCLUSÃO}

Com o aumento do impacto ambiental no mundo é fundamental que mudemos os nossos comportamentos, hábitos e atitudes em relação ao meio ambiente com a finalidade de protegê-lo. Ter a Educação Ambiental como aliada é importante para a conscientização e informação das situações em que o planeta vive.

Pérez-Rodríguez (2017) menciona que a mudança de atitude deve acontecer através do empoderamento das pessoas, formando-as e informando sobre o meio ambiente.

Deste modo, a Educação Ambiental cumpre com esse propósito de proteção, informação e conscientização e quando é aplicada nas empresas, proporciona benefícios para todos os envolvidos. 
As mudanças de atitudes e hábitos sustentáveis no local de trabalho trazem benefícios para as empresas e traz uma imagem positiva aos clientes, gerando também funcionários motivados e comprometidos com o meio ambiente.

Ser uma empresa comprometida com a preservação ambiental e preocupada em não provocar acidente ambiental é um fator importante nos dias de hoje. Para isso é necessário capacitar, formar e sensibilizar todos os trabalhadores para essa missão e a Educação Ambiental tem esse papel.

Os benefícios que a empresa obterá ao ser amiga do meio ambiente são muitos e aplicar atitudes sustentáveis em suas atividades diárias colabora para minimizar os problemas ambientais. A conscientização sobre a conservação do nosso planeta é um dever de todas as pessoas e mudar as atitudes e reflexionar sobre o dano que causamos ao meio ambiente contribuirá para o futuro.

As empresas precisam instruir e formar seus trabalhadores sobre as questões ambientais, mudando hábitos obsoletos por atitudes sustentáveis e proporcionando que essa prática positiva contagie os seus trabalhadores. Crohn e Birnbaum (2010) comentam que é frequente o uso da Educação Ambiental em contexto não formal, mostrando que grande parte da educação é feita além dos limites das escolas.

Ao analisar as respostas do questionário, notou-se que os participantes tinham consciência das ações e ideias adotadas pelas empresas e essa prática vivida no local de trabalho era levada para seus lares. Percebeu-se também que os participantes conheciam bem os propósitos ambientais de suas empresas.

É importante que os funcionários contribuam com as companhias dando ideias e realizando ações positivas através de concursos culturais e recepção de ideais. Assim, afirma-se que ter os trabalhadores unidos para o cumprimento e realização das ações é um ponto fundamental dentro da empresa.

Com esta pesquisa é possível dizer que as companhias têm um grande papel na implementação de ações sustentáveis com a finalidade de reduzir o impacto ambiental.

Segundo Estrada-Vidal e Tójar-Hurtado (2017), ter uma Educação Ambiental é importante em todo os níveis para poder melhorar o meio ambiente e o nosso planeta.

As empresas têm suma importância na inclusão de critérios de sustentabilidade que geram benefício para o meio ambiente. Por outro lado, a inovação tecnológica na produção dos produtos da companhia tem um papel fundamental já que economiza custo às empresas, reduzindo também o impacto ambiental.

De acordo com Cuevas- Zuñiga, Rocha-Lona e Soto-Flores (2016), a sustentabilidade vincula as estratégias empresariais com evidencias de que é possível ter sucesso nas operações já que as empresas devem reconhecer sua responsabilidade mediante a sociedade e o meio ambiente.

A Educação Ambiental aplicada dentro das empresas sensibiliza os trabalhadores para o cuidado ambiental, transmitindo a todos os envolvidos que essa prática pode ser utilizada em diferentes lugares e gera cidadãos conscientes e preocupados com o seu entorno.

Conclui-se dizendo que a Educação Ambiental dentro das empresas e indústrias contribui na resolução dos problemas ambientais e minimizar o impacto ambiental é uma tarefa possível desde que se criem iniciativas $\mathrm{e}$ as apliquem de forma efetiva.

\section{REFERENNCIAS}

\section{BARBA, A. A.; SOLIS, P. C. La}

empresa sustentable en una sociedad

de riesgo. Iztapalapa. Revista de

Ciencias Sociales y Humanidades, vol. 21, no. 48, p. 163-182, 2000.

\section{CALIXTO FLORES, R. Momentos \\ e processos de la investigación \\ ambiental. México: UPN, 2015}

CROHN, K.; BIRNBAUM, M.

Environmental education evaluation:

Time to reflect, time for change.

Evaluation and Program Planning, vol.

33, no.2, pp. 155-158, 2010.
CUEVAS-ZÚÑIGA, Ingrid Yadibel;

ROCHA-LONA, LUis; SOTO-

FLORES, María del Rocío. Incentivos, motivaciones y beneficios de la incorporación de la gestión ambiental en las empresas. Universidad \& Empresa, v. 18, n. 30, p. 131-141, 2016.

DOS SANTOS, Natália Britto; GOULD Rachelle K. Can relational values be developed and changed? Investigating relational values in the environmental education literature. Current opinion in environmental sustainability, vol.13, p. 124'2018

ESTAS son las empresas más sustentables del mundo... y ninguna es mexicana. Expansión, Ciudad de México, 25 de jan. de 2019. Disponivel em: < https://expansion.mx/ empresas/2019/01/25/empresas-massustentables-del-mundo-y-ningunamexicana >. Acesso em: 20 de março de 2019.

ESTRADA-VIDAL, L. I.; TÓJARHURTADO, Juan-Carlos. College student knowledge and attitudes related to Sustainability Education and environmental health. ProcediaSocial and Behavioral Sciences, vol. 237, pp. 386-392, 2017.

FLORENCIO DA SILVA, R.; GARCIÁSERRANO, L.A. "Ações sustentáveis nas empresas: Resultados que fazem a diferença no meio ambiente". In C.B (Coord.). Habilidades Gerenciais: Tudo que um gerente precisa saber, ter e fazer nas organizações (Vol. 1, Cap. 25, pp. 261-267). Campinas: Lopes Editora, 2017.

GUERRA, J.B.S.O.A.; GARCIA, J.; LIMA, M.A.; BARBOSA, S.B;; HEERDT, M.L.; BERCHIN, I.I. A proposal of a Balanced Scorecard for an environmental education program at universities. Journal of Cleaner Production, vol. 172, p. 1674-1690, 2018.

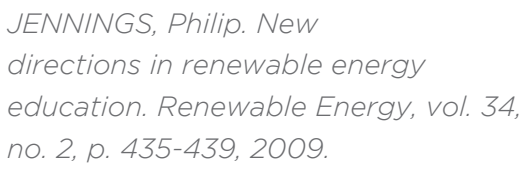

MRAZEK, R. Paradigmas alternativos de investigación en educación ambiental, SEMARNAT - NAAEE. México: Universidad de Guadalajara, 1996. 
PÉREZ-RODRIGUEZ, U.; VARELA-

LOSADA, M.; ÁLVAREZ-LIRES, F.

J.; VEGA-MARCOTE, P. Attitudes

of preservice teachers: Design and

validation of an attitude scale toward

environmental education. Journal of

Cleaner Production, vol. 164, pp. 634-

641, 2017

\section{Recebido em 21 Mar $2019 \quad$ ～Aprovado em 19 Jun 2019}

Rodrigo Florencio da SILVA

Possui o doutorado em Meio Ambiente e Desenvolvimento pelo Centro Interdisciplinario de Investigaciones y Estudios sobre Medio Ambiente y Desarrollo - CIIEMAD, mestre em Educação com especialidade em TIC pela Universidad Interamericana para el Desarrollo - UNID e licenciado em Letras Portuguesas e Inglesas pela Universidade Guarulhos - UnG. É Pesquisador e docente do Instituto Politécnico Nacional - IPN do México. Atua também na Secretaría de Investigación y Posgrado do mesmo Instituto.E-mail: rodriggo_florencio@hotmail.com 